\title{
The Level of Learning Competencies of Vocational Education Teachers in Basic Stage in Irbid Environs from Point View of Schools Principals
}

\author{
Dr. Haitham Mustafa Eyadat \\ Al Balqa Applied University / The Hashemite Kingdom of Jordan \\ Dr. Linda Ahmad Khateeb \\ Faculty of Educational Science, Isra University \\ Eng. Ahmad Mahmoud Khalaf Al Khateep \\ Al Balqa Applied University / The Hashemite Kingdom of Jordan
}

\begin{abstract}
The study aimed to identify the level of educational competencies of vocational education teachers in basic stage in Irbid Environs from the point view of schools principals of (planning and evaluation of teaching, classroom management, and human relationships), in the light of gender, and educational qualification, the study followed the descriptive analytical approach, The researcher prepared a questionnaire consisting of (24) item distributed in the four fields, study sample consisted of all the principals of who numbered (80) principals. The results of study showed that the level of competencies of vocational educational teachers in basic stage from the point of view of school principals is generally at medium average level, with an average (3.65), the adequacy of classroom management came first, with an average of (3.73) and with a high degree of evaluation. In the second place human relations with average of (3.70), and with a high degree of evaluation, in the third place planning for teaching with an average of (3.64), at medium average of evaluation, and in the fourth place teaching evaluation, with an average (3.58), and at medium average. There are statistically significant differences in the level of educational competencies of vocational education teachers in the basic stage from the point of view of principal's duo to the gender variable, and for the benefit of females, and there isn't statistically significant differences duo to the educational qualification. The study recommended the necessity of developing the different educational competencies of the teachers of vocational education, especially those related to evaluation, curriculum development, use of technology in education, and conducting future studies dealing with educational competencies and their relationship to other variables.
\end{abstract}

Keywords: Educational Competencies, Basic stage, Vocational educational teachers. School principals

DOI: $10.7176 / \mathrm{JEP} / 11-24-14$

Publication date:August $31^{\text {st }} 2020$

\section{Introduction}

At the present time, the teacher faces a quantity that verifies the challenges, due to the explosion of knowledge and the technological revolution. In these circumstances, it has become imperative for the teacher to acquire new experiences, skills and knowledge enabling him to develop his performance. Having the necessary experience, skills and knowledge will enable teachers to face challenges, and have a sense of creativity and innovation (AlFatlawi, 2004, 4).

The success of any educational process depends on the teacher, as the teacher is the basis of the educational process, responsible for its success, and the teacher's skills and competence affect his ability to achieve the goals of the educational system. Therefore, it is necessary to work on developing the teacher professionally and expanding his knowledge, and work is required to develop his skills, as the teacher development will work on doing him from carrying out the tasks assigned to him (Al-Momani, 2015, 17).

Thus, teachers must possess the necessary educational competencies. Having the necessary educational competencies will enable teachers to make the desired changes to the educational process, and will enable them to make the educational process a success. These competencies are concerned with the educational situation in several fields, such as the field of teaching planning, the field of evaluation, the field of classroom management, the field of human relations, the field of curriculum development, and other fields (Aoun, 2016, 10).

The teachers' possession of effective educational competencies will make them able to walk the process of teaching and learning according to a clear and specific path that enables them to achieve educational goals, whether these goals are in the short, medium or long term. It should be noted that the absence of these competencies will hinder teachers from achieving their goals, and will make the teaching process a random and disorganized process, and does not enrich student information (Al-Rugaibat, 2018,6).

Therefore, the need for teachers in general, and vocational education teachers in particular for training during 
service has become urgent and necessary, in order to meet the demands resulting from the continuous development in the educational process, methods of teaching professional education, and curricula. These developments require officials in the ministries of education to develop educational competencies for professional education teachers. In this regard, the Study of Squiers (2016: 3) indicated that the amount of teachers' knowledge and the amount of their training will greatly affect their teaching practices and performance, and that the amount of their educational competencies affects the amount of what students learn.

The results of some studies also indicated that teachers in some countries do not possess the necessary educational competencies at the required level, and if they possess them they do not practice them in the teaching process, as the results of the Sullivan study (2008: 6) and the results of the Liveen study (2009: 2) confirmed. Therefore, teachers should be involved in programs that work to prepare them and develop their competencies (Khatib: 19, 2012).

The Enos (2005: 4) study emphasized that programs that aim to develop competencies among teachers are better than other programs, as the latter indicated that these programs enable teachers to communicate information to students effectively. In light of this, the Ministry of Education in Jordan has endeavored in the last ten years to bring about changes in most aspects of the educational process, foremost among which was the development of educational competencies of teachers of different specializations, in order to meet the needs of professional teachers and provide a distinct educational service that is reflected in the teacher's class performance And for both students (Al-Bakri, 2012, 7).

\section{Problem of the Study}

Several studies recommended the need to develop professional competencies among teachers of vocational education for educational competencies such as the Saudi Study $(12,2017)$, where the last study indicated that developing these competencies contributes to raising the level of professional performance among teachers and raising the quality of the teaching process. These competencies include competencies related to planning, evaluation and implementation. In light of the importance of professional competencies, the researchers of the current study believe that conducting a study on the professional competencies of teachers will contribute to its development and will contribute to producing a generation that possesses a lot of knowledge and skills. Therefore, the researchers aim through the current study to know the level of educational competencies of the teachers of vocational education in the basic stage in schools affiliated to the Directorate of the Kasbah of Irbid from the point of view of the principals, and the current study worked to target the relevant competencies in (planning and evaluation of teaching, classroom management, and human relations.

\section{Importance of the Study:}

This study is expected to contribute to the following:

1. Highlighting the strengths and weaknesses of the educational competencies possessed by vocational education teachers for the basic stage from the viewpoint of principals of basic schools in the schools affiliated to the Directorate of the Kasbah of Irbid.

2. This study constitutes an addition to the Arab and local educational literature, especially in light of the scarcity of previous local studies - within the limits of researchers' knowledge - that examined the educational competencies of vocational education teachers.

3. This study sheds light on the role that vocational education teachers play in teaching vocational education to students.

4. This study contributes to providing the necessary data about the educational competencies necessary for vocational education teachers.

5. This study provides a list of the basic educational competencies necessary for a professional education teacher to teach vocational education for the basic stage.

6. The results of this study are expected to assist the educational supervision in developing the process of evaluating the performance of vocational education teachers based on educational competencies.

7. The results of this study help the professional education teacher to develop his educational competencies in the light of the competencies that must be available to him.

8. This study enables researchers to conduct more studies on this subject to develop the educational process and raise the level of student learning.

\section{Objectives of the study:}

The current study aimed to:

1 Determining the level of educational competencies of the teachers of vocational education at the basic stage in schools affiliated to the Directorate of the Kasbah of Irbid from the viewpoint of principals.

2- Disclosing the nature of the differences between the averages of school principals' estimates of the level of educational competencies of vocational education teachers according to gender and educational qualification 
variables.

\section{Study questions:}

The study aims to answer the following:

Q1. What is the level of educational competencies for teachers of vocational education at the basic stage in schools affiliated to the Irbid Kasbah District from the viewpoint of principals?

Q2. What is the nature of the differences between the averages of school principals' assessment of the level of educational competencies of vocational education teachers according to the variables of gender and educational qualification?

\section{Terminology of study:}

Educational competencies (theoretical definition): refers to a set of knowledge, capabilities, and skills that the teacher must possess, such as problem-analysis skill, analysis skill, and communication skill (Hager and Gonczi, 2019, 3)

Educational competencies (procedural definition): refers to a set of knowledge, capabilities and skills that must be possessed by teachers of vocational education for the basic stage in schools affiliated to the Directorate of the Kasbah of Irbid.

Vocational education teacher (theoretical definition): He is the individual who holds an academic degree in the field of vocational education, and works to teach students the subject of vocational education in a school.

The vocational education teacher: (procedural definition): is the vocational education teacher who teaches the basic stage in the basic schools of the Directorate of the Kasbah of Irbid.

The basic stage: (theoretical definition) This stage starts with the first basic grade and ends with the tenth basic grade.

Principals of basic schools: (Procedural definition): They are principals of basic schools affiliated to the Directorate of the Kasbah of Irbid, who have been appointed by the Ministry of Education in Jordan.

\section{Study limits and limitations}

It is not possible to generalize the current research results, due to the nature of the psychometric properties (honesty, consistency) of the study tool, and the study limits are as follows:

Objective limits: The current study aims to target educational competencies in the following areas: planning for teaching, evaluation, classroom management, and human relationships.

Human boundaries: The current study aims to target the directors and principals of schools affiliated to the Irbid Kasbah Directorate, which number (80) male and female principals.

Spatial limits: The current study was conducted in the city of Irbid in Jordan

Time limits: The current study was conducted during the second semester of the 2019/2020 academic year.

\section{Theoretical framework and previous studies}

There are many definitions related to the concept of competency, so Hewitt (2008: 62) defined it as a set of skills, knowledge, and educational methods that teachers practice consistently and continuously while practicing their work. Chuadhry (2012: 16) defined her as being able to do a certain activity according to specific criteria. Aldreej $(2012,43)$ defines it as "acquired abilities that allow behavior and work in a specific context, and that it consists of knowledge, skills and trends combined in a complex way, which the individual uses to confront any problem and find solutions to it." The Education Review Office In Florida (2005) referred to in his return (2010, 22) has also been defined as: "The ability to perform and possess behavioral patterns or knowledge that appear in an individual's behavior in a manner that guarantees achieving the desired goals."

\section{Educational Competence and its Importance:}

The teacher's educational competencies play an important role in the educational process, and the teacher's educational competencies have received a lot of attention since the second half of the twentieth century in the United States, and this interest is due to many factors. Examples of these factors include: the emergence of educational techniques, the emergence of learning programs, and the emergence of many evaluation tools, such as the style of note card, and feedback. In light of this interest, great attention has been paid to teacher training, capacity development and holding training workshops. Nevertheless, many teachers still need training and development (Al-Ajrami, 31, 2011).

Dfee (2016: 5) has indicated that learning enables a person to unleash his talents and abilities and exploit it. Therefore, the teacher preparation process is an important process, as this process is reflected in the outputs of the educational system, the development of society, and is reflected in the stock of knowledge that members of society possess, Abu Shama $(8,2011)$ pointed out that providing the teacher with educational competencies will develop the educational science, and he pointed out that these competencies include: critical thinking from the educational 
learning process of the teacher.

Educational competencies play an important role in teacher preparation and training programs, where teacher development will develop the educational process, and raise the quality of education provided by schools, and teacher development will be positively reflected on their behavior and teaching performance, and teacher development is important because it plays an essential role in the educational process (Jarwan , 2012).

There are many educational competencies that must be available to the teacher in order to teach students efficiently, and contribute to the progress of society, and the current study aims to target the following competencies among teachers of vocational education for the basic stage:

First: Teaching planning: the teaching plans represent the map that guides teachers towards the path that must be followed, it determines their orientations and increases the degree of their confidence in the teaching procedures that they make and the decisions they implement, and the educational plans enable the teachers to achieve their goals, and the educational plans enable the teachers to Achieving their goals and making their steps more organized and sequential, Katame, 2013,21), and the teaching planning process is defined as a mental process that the teacher undertakes to achieve specific educational goals and increase the effectiveness of the teaching process (Al-Fatlawi, 2004, 1).

Second: Teaching Evaluation: This is represented by the teacher's ability to evaluate the student during the teaching process, and to provide appropriate feedback to the student, in order to achieve the goals that were previously set (Katame, 2013, 5).

Third: Classroom Management: This is represented by the teacher's ability to manage the classroom learning situation, and to achieve classroom control for students during the learning process, in order to raise students 'focus and attract their attention, and increase participation in classroom activities (Qatami, 2013, 5).

Fourth: Human Relations: This competence indicates the extent of the teacher's skill in dealing effectively with students and creating a spirit of teamwork among them and establishing social relations with students, and this competency is defined as the ability of the teacher to interact effectively with his students, and the teacher enjoying this competence is characterized as a sophisticated human being, He is aware of his strengths and weaknesses, renewed, and able to make a change in the school he works in. This person is characterized as having selfconfidence, trusting others, and realizing the psychological and social needs of his students (Al-Butti, 2010, 2).

\section{Previous studies:}

Researchers have reviewed a number of studies, and they are listed below according to the year of publication from oldest to most recent.

Hou (2012) conducted a study entitled (the important technological competencies needed by international secondary school teachers, and the degree of their application), (The important technological competencies need by International secondary schools teachers and their applying them), and the study aimed to know the most important educational competencies needed by stage teachers High school in order to teach students efficiently. An analytical descriptive approach has been adopted. The study sample consisted of 411 high school teachers in Korea, and a questionnaire was distributed to the sample. This questionnaire highlights three competencies, which shows that the degree of possession of educational competencies by teachers High school in Korea is high.

Al-Hijaya conducted (2013) a study entitled (The extent of vocational education teachers in schools of the Kasbah of the Tafila Department of professional competencies from the point of view of school administrators), and the researcher's goal is to find out the degree of professional competencies practiced by teachers of vocational education in schools of the Kasbah of Tafila from the viewpoint of school administrators, The descriptive and analytical approach was adopted, and the questionnaire worked on extending light to (45) sufficiency, distributed over five areas, and the study sample consisted of 64 managers and directors, and it was found that the level of professional education teachers practice of professional competencies is high, and the field of planning came in the first place, and the field came Curricula development ranked last

Qasmi and Khurshid (2015) conducted a study entitled (the educational competencies of primary school teachers in Pakistan and their relationship to their job performance), (Educational competencies of primary school teachers in Pakistan and their relationship to job performance), and the study aimed to identify the educational competencies of school teachers In Pakistan, the study aimed to know the relationship of the educational competencies of these teachers to their job performance. The study sample consisted of (75) male and female teachers, and (225) male and female students. The results showed a statistically significant positive relationship between the possession of educational competencies and job performance, and it was found that The female teachers have more educational competencies than their male counterparts.

Al-Ajmi (2016) conducted a study entitled (the degree of mathematics teachers 'possession of the basic stage in Kuwait for educational competencies from their point of view), and the study aimed to know the extent to which mathematics teachers in the basic stage in Kuwait possess educational competencies from their point of view, and a questionnaire was prepared highlighting thirty Adequacy, and the sample consisted of 108 female and male teachers, and it was found that the teachers 'possession of mathematics for the basic stage in Kuwait for educational 
competencies is considered high in all fields, and there are no statistically significant differences between teachers with regard to the level of possession of competencies that can be attributed to the academic qualification or years of experience .

Aoun (2016) conducted a study entitled (The degree of teachers in the basic stage of educational competencies and the degree of their exercise in it from the point of view of educational supervisors in Yemen), and the study aimed to know the level of ownership of educational competencies by teachers of vocational education in the basic stage and the degree of their exercise of it, and the study aimed to know This is from the perspective of the educational supervisors in Taiz, Yemen, and the descriptive approach was used, and a questionnaire consisting of (51) sufficiency was employed, the study sample consisted of (34) supervisors, and it was found that the degree of ownership and employment of educational competencies by basic stage teachers is average.

The Saudi (2017) conducted a study entitled (The extent of the practice of vocational education teachers in Tafila governorate for educational competencies in the light of some variables), and the study aimed to know the degree of vocational education teachers in the Tafila governorate for educational competencies, and the descriptive approach was adopted, and a questionnaire was used that shed Highlight (68) educational adequacy, and the questionnaire was applied to (77) male and female teachers, and it was found that the degree of professional education teachers practicing educational competencies is low, and that there are no differences in the practice of competencies that can be traced to the variables of the educational qualification and gender.

Al-Kilani (2017) conducted a study entitled (the level of performance of teachers of vocational education in Jordan for the teaching skills necessary for them), and the study aimed to know the level of teaching skills of vocational education teachers in Jordan, the descriptive approach was adopted, and the questionnaire was applied to (154) managers and managers, It was found that the level of teaching skills of professional education teachers is average, and that there were no differences in the level of performance among teachers due to gender variations, educational qualification, and experience.

\section{Comment on previous studies}

The current study was similar to the Hou study (2012) and the Hijaya study (2013) in terms of approach, as these two studies followed the descriptive analytical approach, and the current study was similar to the Saudi study (2017) and Al-Ajami study (2016) in terms of the tool of collecting information, where These two studies worked on using a questionnaire to collect data, and the current study was similar to the Al-Ajmi study (2016) in terms of subject matter, where the last study worked on knowing the degree of teachers of mathematics subject for basic stage in Kuwait for educational competencies from their point of view, and the current study differed with a study Aoun (2016) in terms of spatial boundaries, where Aoun (2016) was conducted in Yemen. As for the current study, it was conducted in Irbid, Amman.

\section{Study procedures}

Study Approach:

The study adopted the descriptive analytical approach, and this approach is used to describe capabilities, needs, methods, practices, societies and policies according to the study questions, and this approach works to describe a phenomenon or know the recurring pattern in a series of data (Loeb et al., 2017, 3)

\section{Study community:}

The study population consisted of all principals of the primary schools affiliated with the Irbid Kasbah schools and workers during the school year (2019-2020), and they numbered (80) principals and principals, according to the records of the Ministry of Education, where researchers reviewed the records of the Ministry of Education in Jordan

\section{The study sample:}

The study sample consisted of all members of the study community consisting of (80) managers and directors, and table (1) shows the distribution of the study sample according to the study variables: gender and educational qualification.

Table (1): Distribution of the study sample according to its characteristics, the two gender variables, and the educational qualification.

\begin{tabular}{|c|c|c|c|}
\hline Variables & Category & Repetition & percentage \\
\hline \multirow{3}{*}{ Gender } & Male & 36 & $\% 45$ \\
\cline { 2 - 4 } & Female & 44 & $\% 55$ \\
\cline { 2 - 4 } & Total & 80 & $\% 100$ \\
\hline \multirow{2}{*}{ Qualification } & Bachelor & 56 & $\% 70$ \\
\cline { 2 - 4 } & Postgraduate & 24 & $\% 30$ \\
\cline { 2 - 4 } & Total & 80 & $\% 100$ \\
\hline
\end{tabular}




\section{Study Instrument:}

The researchers prepared the study instrument after reviewing previous studies in the field of professional educational competencies for teachers, such as the study of: (Saudi, 2017, and Kilani, 2017; and Aoun, 2016). And its primary form consisted of (28) items distributed among the four areas of the questionnaire. ) Paragraphs, teaching evaluation (6), classroom management (6) paragraphs, human relations (6) paragraphs, and in front of each paragraph are five alternatives to the answer, which are of the degree: (Strongly agree, agree, neutral, do not agree, strongly do not agree).

\section{Criteria for classifying mathematical averages:}

Likert five-point scale was adopted, which consists of five classification grades, namely: I strongly agree, agree, neutral, do not agree, and do not strongly agree, and these degrees represent the following points, respectively: 5, $4,3,2,1$, and the study was approved The following classification scale to describe the level of the averages values:

1-2.33: low

2.34-3.67: medium

5 3.68: High

These standards are based on the following criteria:

The amount of increase between each of the two categories = (the largest value - the lowest value) / the number of categories required

$(5-1) / 3=1.33$

To verify the validity and reliability of the study tool, the researchers took the following steps:

Validate the study instrument:

To ensure the validity of the study instrument, the validity of the arbitrators and structural constructively of the scale were used, as follows:

\section{a. Virtual validity}

The apparent sincerity of the instrument was confirmed, as the tool was presented to ten (10) arbitrators from professors of curricula and teaching methods in Jordanian universities, and they were asked to express an opinion on the instrument's paragraphs, in terms of their suitability of the study goals, the paragraph's affiliation to its field, and its linguistic clarity. Based on the results of the arbitration, some of the paragraphs were reformulated, some of them were merged with other paragraphs, some of the paragraphs were transferred from one field to another, and all arbitrators indicated that the tool is capable of achieving the objectives of the study, and adjustments were made to the tool in light of the arbitrators 'comments to come out with the final version of the instrument.

\section{B. Constructive honesty}

For the purpose of extracting constructive honesty indicators for all paragraphs of the tool, it was applied to a survey consisting of (15) managers and directors from outside the study sample. The survey sample was chosen from the principals of government basic schools in Amman. Pearson correlation coefficients were calculated between each vertebrae and the field to which it belongs and the scale as a whole. These coefficients were calculated by means of the test-retest method, whereby the questionnaire was distributed to an exploratory sample similar to the study sample of (20) managers, and the questionnaire was distributed again to the members of the sample Exploratory studies after two weeks have passed, and it has been shown that the correlation coefficients between paragraphs and areas of the study tool exceed (0.40), and with the tool as a whole more than (0.30), all of which are statistically significant at the level of statistical significance $(.050 .05 \alpha)$. This indicates a strong correlation coefficient for the vertebrae and its areas with the instrument as a whole, which are acceptable parameters for the application of the study.

The stability of the study instrument:

To ensure the stability of the tool, the stability was calculated by using the method of internal consistency by calculating the values of the coefficients (Cronbach alpha), where the coefficient of the stability of Cronbach alpha was extracted, and Table (2) shows the results of the stability coefficient of the questionnaire according to its fields.

Table (2) the values of the Cronbach alpha parameters for the resolution of each and every field

\begin{tabular}{|l|c|c|}
\hline \multicolumn{1}{|c|}{ Fields } & No. of paragraph & Cronbach alpha parameters \\
\hline Teaching planning & 6 & 0.82 \\
\hline Teaching evaluation & 6 & 0.82 \\
\hline Classroom management & 6 & 0.87 \\
\hline Human relationships & 6 & 0.85 \\
\hline The instrument as a whole & 24 & 0.84 \\
\hline
\end{tabular}

Table (2) shows that the study instrument has acceptable levels of stability for conducting the study, and the 
total stability coefficient of the questionnaire was $(0.84)$, and the stability factors ranged between $(0.82-0.87)$.

\section{Statistical treatments:}

The following statistical treatments were used to analyze the data required to answer the two study questions:

Arithmetic mean, standard deviations, percentages, test (v), and Cronbach Alpha.

Presentation and interpretation of results:

In this part, the results of the two study questions were presented, discussed and explained, as follows:

First: Presenting the results related to answering the first question: What is the level of educational competencies among teachers of vocational education in the basic stage in Irbid Governorate from the point of view of managers? To answer this question, arithmetic averages and standard deviations for the level of educational competencies among teachers of vocational education for the basic stage were calculated from the point of view of managers.

Table (3) descriptive statistics of the level of educational competencies among teachers of vocational education for the basic stage from the viewpoint of the managers.

\begin{tabular}{|l|c|c|c|c|}
\hline \multicolumn{1}{|c|}{ Sufficiency } & Mean & standard deviation & Level & Rank \\
\hline Teaching planning & 3.64 & 0.94 & Moderate & 3 \\
\hline Classroom management & 3.73 & 0.85 & High & 1 \\
\hline Human relationships & 3.70 & 0.78 & High & 2 \\
\hline Teaching evaluation & 3.58 & 0.75 & Moderate & 4 \\
\hline Kidney & 3.65 & 0.88 & Moderate & \\
\hline
\end{tabular}

The table shows that the total arithmetic average of the study sample estimates towards educational efficiencies among vocational education teachers for the basic stage has reached (3.65), and is considered an average, and the arithmetic mean ranges for fields of educational competencies ranged between (3.58 - 3.73), where the classroom management competencies ranked first with an arithmetic average (3.73), with a high degree of evaluation, and secondly, the adequacy of human relations, with an arithmetic average (3.70), and with a high degree of evaluation. 0.75), with an average score.

To reveal the level of educational competencies among the teachers of vocational education for the basic stage from the point of view of individual directors, the arithmetic averages and standard deviations for the study sample estimates were calculated on the paragraphs of each field as follows:

Table (4) descriptive statistics of the study sample estimates for teaching planning competencies.

\begin{tabular}{|c|c|l|c|c|c|}
\hline Ranking & $\begin{array}{l}\text { Paragraph } \\
\text { no. }\end{array}$ & \multicolumn{1}{|c|}{ Paragraph } & Mean & $\begin{array}{c}\text { standard } \\
\text { deviation }\end{array}$ & Level \\
\hline 1 & 4 & $\begin{array}{l}\text { Provides quality education opportunities for } \\
\text { students by preparing for and pre-preparing for } \\
\text { the class. }\end{array}$ & 3.70 & 0.75 & High \\
\hline 2 & 3 & $\begin{array}{l}\text { Determines the appropriate methods for } \\
\text { introducing the lesson and its objectives. }\end{array}$ & 3.68 & 0.72 & Moderate \\
\hline 3 & 6 & $\begin{array}{l}\text { Establishes the teaching plan and adjusts it } \\
\text { according to the feedback from the application. }\end{array}$ & 3.65 & 0.89 & Moderate \\
\hline 4 & 2 & $\begin{array}{l}\text { Choose the appropriate methods and techniques } \\
\text { to achieve the lesson objectives. }\end{array}$ & 3.63 & 0.90 & Moderate \\
\hline 5 & 5 & $\begin{array}{l}\text { Determines the teaching methods and techniques } \\
\text { appropriate to the subject and objectives of the } \\
\text { lesson. }\end{array}$ & 3.60 & 0.80 & Moderate \\
\hline 6 & 1 & $\begin{array}{l}\text { Determines the methods of implementing the } \\
\text { appropriate plan to achieve the objectives of the } \\
\text { lesson. }\end{array}$ & 3.55 & 0.86 & Moderate \\
\hline
\end{tabular}

Table (4) shows that five paragraphs of the field of teaching planning came with an average level of estimation, and one paragraph came with a high level of appreciation, as it turns out that the total arithmetic average of the study sample's estimates of the level of study planning adequacy level reached (3.64) and an average level of estimation, and ranged Arithmetic mean for teaching planning paragraphs between (3.55 - 3.70). Where the highest one for Paragraph (4) "provides good education opportunities for students through preparation and preparation of the pre-session." With an average mathematical average of (3.70), and with a high level of appreciation, while Paragraph (1) "determines the methods of implementing the appropriate plan to achieve the objectives of the lesson." At the lowest average and in the last rank among the paragraphs of the field of teaching planning. The overall mean of the planning area was (3.64), with an average level of estimation.

These results mean that teachers of vocational education in basic schools in the Kasbah of Irbid possess 
adequate planning for teaching at an intermediate level, and below the required level, and this result may be due to the inability of some teachers to integrated planning for the classroom position, or it may be that the teacher has prepared the plan to implement the learning Written well, but during implementation it resort to improvisation and randomness in the implementation of learning without being restricted to planning, and thus the teacher finds himself executing the learning randomly without commitment to organized planning of the lesson, the competent, competent teacher who prepared a sound preparation is the one who is fluent in the arts of planning processes and preparing for the lesson and preparing for it Bearing in mind the requirements for planning a good lesson in terms of formulating the goals, formulating measurable behavioral, choosing the appropriate preliminary, determining the educational methods and means that facilitate the teaching process and allocating the appropriate time to the steps of the lesson in order not to waste the class time and give each goal its right.

This result is consistent with the study (Saudi, 2017; Al-Kilani, 2016; and Aoun, 2016). Which showed that the level of educational competency of teachers is average. They differed with the result of a study (Al-Ajmi, 2016; and Al-Hijaya, 2013). Where we found that the level of educational competencies of teachers is high.

Table (5) descriptive statistics of the study sample estimates for classroom management competencies.

\begin{tabular}{|c|c|l|c|c|c|}
\hline Ranking & $\begin{array}{c}\text { Paragraph } \\
\text { no. }\end{array}$ & \multicolumn{1}{|c|}{ Paragraph } & Mean & $\begin{array}{c}\text { standard } \\
\text { deviation }\end{array}$ & Level \\
\hline 1 & 9 & $\begin{array}{l}\text { It provides the appropriate class environment for } \\
\text { learning to take place. }\end{array}$ & 3.80 & 0.78 & High \\
\hline 2 & 12 & $\begin{array}{l}\text { Use appropriate communication with students, } \\
\text { such as body language, gestures, and facial } \\
\text { expressions, to encourage students to learn. }\end{array}$ & 3.77 & 0.89 & High \\
\hline 3 & 10 & $\begin{array}{l}\text { Students return to self-control of their behavior } \\
\text { away from the use of punishment. }\end{array}$ & 3.75 & 0.90 & High \\
\hline 4 & 7 & Keen to build human relationships with students. & 3.70 & 0.98 & High \\
\hline 5 & 8 & $\begin{array}{l}\text { It provides successful class management during } \\
\text { the learning progress. }\end{array}$ & 3.68 & 0.97 & High \\
\hline 6 & 11 & It does class participation for all students. & 3.60 & 0.89 & Moderate \\
\hline Total & & & 3.73 & 0.85 & Moderate \\
\hline
\end{tabular}

Table (5) shows that five paragraphs of the adequacy of classroom management came with a high level of estimation, and one paragraph came with an average level of estimation, as it turns out that the total arithmetic mean of the study sample estimates for the level of classroom adequacy level reached (3.73) and with a high level of estimation, and ranged The arithmetic mean for the passages of this adequacy is between $(3.60-3.80)$ Where the highest one for Paragraph (9) "provides the appropriate classroom environment for learning to take place." With an average score of (3.80), and with a high level of appreciation, while Paragraph (11) says, "It does class participation for all students." At the lowest average and in the last ranks of the vertebrae, "and the overall average score (3.73) was at a high level of appreciation.

These results mean that teachers of vocational education in basic schools in the Kasbah of Irbid possess the adequacy of classroom management at a high level, and within the required level, and this result may be due to the teachers 'knowledge of classroom control methods and educational attitude management, which helped the teacher create a learning environment, and attract students' attention towards learning, And students collaborated with the teacher to achieve a class-appropriate learning environment.

It is consistent with the results of a study (Al-Ajmi, 2016; and Al-Hijaya, 2013). And we showed that the level of sufficiency of classroom management among teachers is high. This result differs with the study (Saudi, 2017; Al-Kilani, 2016; Aoun, 2016). Which showed that the level of adequacy of classroom management among teachers is average.

Table (6) descriptive statistics of the study sample estimates for the competencies of human relations.

\begin{tabular}{|c|c|l|c|c|c|}
\hline \hline 1 & 14 & He works with fellow teachers with a one team spirit. & 3.78 & 0.89 & High \\
\hline 2 & 17 & Inculcates patriotic, patriotic and human values. & 3.77 & 0.86 & High \\
\hline 3 & 15 & It takes into account students' social and psychological conditions. & 3.75 & 0.89 & High \\
\hline 4 & 13 & Students develop positive feelings about school. & 3.70 & 0.90 & High \\
\hline 5 & 18 & Connect the subject of the lesson with current events and life problems. & 3.65 & 0.88 & Moderate \\
\hline 6 & 16 & He treats students with respect and shows positive emotions. & 3.60 & 0.90 & Moderate \\
\hline Total & & & 3.70 & 0.78 & High \\
\hline
\end{tabular}

Table (6) shows that four passages from the field of human relations came with a high level of estimation, and two paragraphs came with an average level of estimation, as it turns out that the total arithmetic mean of the study sample estimates for the level of adequacy of human relations among teachers reached (3.71) and a high level of appreciation, The arithmetic mean for the paragraphs of human relations ranged between (3.60 - 3.78). 
Where he was the highest of Paragraph (14) "He works with his fellow teachers with the same team spirit." With a mathematical average (3.78), and a high level of appreciation, while the paragraph (16) "deals with students with respect and shows positive feelings towards them" came at the lowest average and ranked last among the paragraphs of human relations, while the overall average for the field was (3.71) And a high level of appreciation.

These results mean that teachers of vocational education in basic schools in the Kasbah of Irbid possess the sufficiency of managing human relations with students and teachers at a high level, and within the required level, and this result may be due to the nature of vocational education teachers and their tendency to form social and human relationships with others, and to their knowledge of the importance of practicing relationships Humanity in school, because of its positive impact on the formation of a good reputation for him among others.

This result is consistent with the results of a study (Al-Ajmi, 2016; Al-Hijaya, 2013). It showed that the level of human relations among teachers is high. This result differs with the study (Saudi, 2017; Al-Kilani, 2016; Aoun, 2016). Which showed that the level of sufficiency of human relations among teachers is average.

Table (7) the descriptive computational statistics and the deviation of the grades of the sample individuals. Teaching evaluation competencies

\begin{tabular}{|c|c|c|c|c|c|}
\hline Ranking & $\begin{array}{l}\text { Paragraph } \\
\text { no. }\end{array}$ & Paragraph & Mean & $\begin{array}{l}\text { standard } \\
\text { deviation }\end{array}$ & Level \\
\hline 1 & 21 & It uses pre-, dual, and post-assessment tests. & 3.70 & 0.75 & High \\
\hline 2 & 24 & $\begin{array}{l}\text { Uses educational activities that take into } \\
\text { account individual differences among students. }\end{array}$ & 3.65 & 0.82 & Moderate \\
\hline 3 & 22 & $\begin{array}{r}\text { Creates treatment plans for underachieving } \\
\text { students }\end{array}$ & 3.60 & 0.84 & Moderate \\
\hline 4 & 19 & Uses methods of reinforcement. & 3.55 & 0.93 & Moderate \\
\hline 5 & 20 & $\begin{array}{r}\text { Students work during the implementation of } \\
\text { the educational activities calendar. }\end{array}$ & 3.50 & 0.86 & Moderate \\
\hline 6 & 23 & $\begin{array}{r}\text { Uses appropriate evaluation methods to achieve } \\
\text { the objectives of the lesson. }\end{array}$ & 3.45 & 0.85 & Moderate \\
\hline Total & & & 3.58 & 0.94 & Moderate \\
\hline
\end{tabular}

It is evident from Table (7) that (5) the items in the teaching evaluation field had a medium level of appreciation.

And one paragraph came at a high level, as it turns out that the total arithmetic mean of the estimates of the members of the study sample for the level of adequacy of the teaching evaluation for teachers reached (3.58) and an average level of appreciation, and the arithmetic mean ranges for the paragraphs between $(3.45-3.70)$. Where the highest one was for Paragraph (21), "it uses pre-, post- and post-assessment tests." With an arithmetic average (3.70), and a high level of appreciation, while paragraph (23) came, "Uses appropriate evaluation methods to achieve the objectives of the lesson." At the lowest average and in the last rank among the teaching evaluation paragraphs. The overall average was (3.45) and with a high level of appreciation.

These results mean that the teachers of vocational education in basic schools in the Kasbah of Irbid do not have sufficient evaluation of teaching in the appropriate form of the learning process, and this result may be due to the lack of knowledge of vocational education teachers of the methods and methods of evaluation followed in the educational situation.

This result is consistent with the study (Al-Saudi, 2017; Al-Kilani, 2016; and Aoun, 2016). Which showed that the level of teacher evaluation for teachers is average, and varies with the result of a study (Al-Ajami, 2016; and Al-Hijaya, 2013). Where we showed that the level of teacher evaluation for teachers is high.

Presentation and discussion of the results of the second question: Are there statistically significant differences at the level $(\alpha=0.05)$ between the averages of school principals estimates of the level of educational competencies of the teachers of vocational education attributed to the variables of gender and educational qualification?

To answer the question, arithmetic averages and standard deviations were extracted and a T-test ( $\mathrm{t}$-test) was used for the study sample estimates on the instrument's paragraphs according to the variables of the educational qualification and gender. The following tables show that.

\section{Suggestions:}

In light of the study's findings, the researchers recommend the following:

1- Holding training programs for professional education teachers on teaching methods, and the importance of employing educational techniques

2- School principals should encourage professional education teachers to use appropriate evaluation methods to achieve the objectives of the lesson

3- School principals should encourage professional education teachers to use the incentive method

4- Working on evaluating teachers periodically to provide them with feedback that enables them to use the methods of evaluation that are compatible with the objectives of the lessons. 
5- Holding workshops to spread awareness among teachers about the importance of respecting students and establishing good social relations with them, as this will positively reflect on the quality of education, the school climate, and the performance of the school as a whole.

\section{Reference}

Al-Bakri, Fayez. (2012). Developing a supervisory communication process between educational supervisors and teachers in general education schools in the Asir region, unpublished doctoral thesis, Department of Educational Administration and Planning, College of Education, King Khalid University.

Al-Butti, Abdullah (2010). "Administrative Competencies Required for Education Managers in the Saudi Professional Kingdom", unpublished PhD thesis, King Saud University, Riyadh, Saudi Arabia.

Jarwan, Fathi (2012). Teaching strategies for teachers of gifted students. 2nd i, Oman: House of Fikr.

Al-Khatib, Ahmed (2012). Teacher training on adequacy (skill and performance), second cycle, Jordanian Journal of Educational Sciences, 3 (20), 122-154. 2012.

Al-Hijaya, Iyad Ali (2013). The extent of vocational education teachers in the schools of the Kasbah of Tafileh District for professional competencies from the viewpoint of school principals. Al-Azhar University Journal (Human Sciences), 1 (1): 311--360.

Al-Dorij, Muhammad. (2012). Competencies in education. Casablanca: Dar Al Uloom for Investigation, Printing and Publishing.

Sergeants, Major (2018). The degree to which Islamic education teachers possess educational competencies in Jordan. Professional Journal of Research Publishing, 28 (2), 22-54.

Abu Shamma, Wafa (2011). The effect of a training program on developing professional knowledge in engineering for mathematics teachers for the basic stage and improving the achievement of their students in Palestine, Amman, unpublished doctoral thesis, University of Jordan, Amman.

Saudi, Muhammad (2017). The extent of vocational education teachers in the Tafila Governorate for educational competencies in light of some variables, unpublished Master Thesis, Mu'tah University, Karak.

Al-Ajrami, Basem (2011). The effectiveness of a proposed training program to develop the professional competencies of students of basic education teachers at Al-Azhar University, Gaza in light of the teacher preparation strategy, unpublished Master Thesis, Al-Azhar University, Gaza.

Al-Ajami, Fayez. (2016). The degree to which mathematics teachers for the basic stage in Kuwait possess educational competencies from their point of view. Unpublished MA thesis, Al al-Bayt University, Mafraq, Jordan.

Aoun, Salem (2016). The degree of teachers owning the basic stage of educational competencies and their degree of practicing it from the point of view of educational supervisors in Yemen, Jordanian Journal of Educational Sciences, 34 (2), 4563-4575.

Return, Hadeel (2010). Administrative competencies of principals of primary schools in the Madaba governorate and their relationship to the morale of teachers. Unpublished Master Thesis, Middle East University, Amman, Jordan.

Al-Fatlawi, Suhaila (2004). Teaching competencies, concept, training, performance, 2nd edition. Amman: Sunrise House for Publishing and Distribution.

Qatami, Nayfeh. (2013). Effective teaching skills. Amman: Dar Al-Fikr for publication and distribution.

Al-Kilani, Saeed (2017). The level of performance of vocational education teachers in Jordan with the teaching skills necessary for them. Unpublished Master Thesis, Al Yarmouk, Irbid.

Al-Momani, Muhammad (2015). The extent to which social studies teachers possess the necessary educational competencies for the basic stage, unpublished Master Thesis, Yarmouk University, Irbid.

\section{Foreign reference}

Chuadhry, M. A. and Shah, S. (2012). "Impact of Managerial Skills Learnt Through MA Educational Planning Management Programme of Alou on the Performance of Institutional Heads". Turkish Online Journal of Distance Education, 13 (2), 370 - 381.

Enos, D. (2005). Competency-Based Non-Compatency Based Teacher Education, Journal of Teacher Educaton, 27(2).

Hager, Paul \& Gonczi, Andrew. (2009). What is competence?. Medical Teacher. 18. 15-18. $10.3109 / 01421599609040255$.

Hewitt, W. Thomas. (2008). The educational competencies that basic stage teachers need to practice the teaching profession effectively. Teaching National Council for the social، Washington.

Hou, K. (2012). The important technological competencies need by International secondary schools teachers and their applying them، Dissertation Abstract,62 (1) 657- 658.

Liveen, S. (2009). Defining a good teacher simply. Modern English Teacher. 17 (1)، 5-14.

Loeb, S., Dynarski, S., McFarland, D., Morris, P., Reardon, S., \& Reber, S. (2017). Descriptive analysis in 
education: A guide for researchers. (NCEE 2017-4023). Washington, DC: U.S. Department of Education, Institute of Education Sciences, National Center for Education Evaluation and Regional Assistance

Qasmi, A, and Khurshid, D. ( 2015). Educational competencies of primary school teachers in Pakistan and their relationship to job performance. Unpublished Doctoral dissertation. Ohio State University, Ohio, USA.

Squires, Y. (2016). Adult learner and academic achievement: The role of self-efficacy، self-regulation, and motivation. (ERIC Document Reproduction Service No. ED 379216). 